\title{
Relative stability of subcooled flow boiling on non- uniformly heated, inclined flat surface
}

\author{
W.W. Lin, J.C. Yang, D.J. Lee* \\ Department of Chemical Engineering, National Taiwan University, Taipei 10617, Taiwan
}

Received 2 December 1998; received in revised form 15 May 1999

\begin{abstract}
This work elucidated the effects of liquid subcooling on the relative stability between nucleate boiling and film boiling on an inclined surface. At each heater's orientation and liquid subcooling of $0-20 \mathrm{~K}$, the co-existing heat fluxes were found, from which the equilibrium heat flux $\left(q_{\mathrm{c}}\right)$ was identified. Experimental results indicate that $q_{\mathrm{c}}$ increases with liquid subcooling, with the maximum $q_{\mathrm{c}}$ occurring at rotating the surface by $90^{\circ}$ from the horizontal position. In addition, equal-area criterion was adopted to properly interpret the experimental results. The shift in transition boiling curve correlated well with the change in relative stability when varying the heater orientation and liquid subcooling. (C) 2000 Elsevier Science Ltd. All rights reserved.
\end{abstract}

Keywords: Boiling; Subcooling; Orientation; Relative stability

\section{Introduction}

The extent to which heater orientation influences the pool boiling heat transfer efficiency has received increasing attention [1-19]. When rotation around the horizontal axis is parallel to the flow direction, nucleate boiling efficiency increases with orientation angle at a low heat flux region, and becomes insensitive to orientation when the heat flux becomes high [9] (Moissis-Berenson Transition, [20]). Previous investigations indicated that the critical heat flux (CHF) and minimum heat flux (MHF) decrease when the surface is inclined $[7,11,14]$. In film boiling regime, Nishikawa et al. [9] and Nishio and Chandratilleke [11] observed that the maximum heat transfer efficiency occurs when the heater is turned vertically on its side. Githinji and

\footnotetext{
* Corresponding author. Tel.: +886-2-2362-5230; fax: + 886-2-2362-3040.

E-mail address: djlee@ccms.ntu.edu.tw (D.J. Lee).
}

Sabersky [1] and Jung et al. [7], on the other hand, revealed a monotonically decreasing heat transfer efficiency at a greater orientation.

According to a related investigation, liquid subcooling can markedly enhance boiling heat transfer efficiency as well as the CHF [21]. Applying subcooled liquid on an inclined boiling surface is a common practice. On an inclined heated surface, El-Genk and Guo [13] and Haddad and Cheung [18] considered the effects of liquid subcooling on pool boiling characteristics.

A few studies considered subcooled flow boiling on an inclined heated surface [22-25]. As the liquid flow rates increase, Gersey and Mudawar [22] revealed a diminishing dependence of $\mathrm{CHF}$ on surface orientation. Brusstar et al. [24] elucidated the effects of subcooling and heater orientation on the CHF and the bubble residence time. Their results indicated the following: (1) at a low liquid flow rate of $0.04 \mathrm{~m} / \mathrm{s}$, the $\mathrm{CHF}$ behaves as in pool boiling system; (2) the bubble residence time is inversely proportional to the $\mathrm{CHF}$ at 

Nomenclature
$q_{\mathrm{b}} \quad$ boiling heat flux, $\mathrm{W} / \mathrm{m}^{2}$.
$q_{\mathrm{c}} \quad$ equilibrium heat flux, $\mathrm{W} / \mathrm{m}^{2}$.
$q_{\mathrm{F}} \quad$ coexisting film boiling heat flux, $\mathrm{W} / \mathrm{m}^{2}$
$q_{\mathrm{N}} \quad$ coexisting nucleate boiling heat flux, $\mathrm{W} / \mathrm{m}^{2}$
$\Delta T_{b} \quad$ surface superheat, $\mathrm{K}$
$\Delta T_{\text {sub }}$ liquid subcooling, $\mathrm{K}$
$V \quad$ voltage, $\mathrm{V}$
$\theta \quad$ orientation angle, degree

all heater orientations; (3) although increasing the liquid subcooling reduces the vapor generation amount, the bubble residence time at $\mathrm{CHF}$ is independent of subcooling. Based on these findings, a subsequent work [25] proposed a model to describe the CHF for pool and flow boiling.

Steady and unsteady state two-mode boiling (nucleate and film boiling) on an electrically heated wire has been thoroughly examined [26-28]. According to these works, both the nucleate boiling curve and the film boiling curve comprise the stable and metastable regimes, respectively. A heater under metastable nucleate boiling mode can tolerate a finite-magnitude disturbance (dry patch) to prevent burnout. Therefore, identifying the points that separate stable and metastable regimes on a boiling curve is a relevant task. Experimental procedures for identifying these points in a wire boiling system can be found elsewhere [26].

Industrial applications involving boiling frequently adopt conductive heating. According to the results of wire boiling, similar stable and metastable regimes appear to exist on a conductively heated, flat plane heater. Our earlier investigations examined the relative stability between nucleate and film boiling of methanol on a flat plane heater under a low-velocity forced flow condition [29-31]. To our knowledge, only one previous work elucidated the relative stability between nucleate and film boiling on an inclined, conductively heated surface [32]. However, those investigations [2932] did not investigate the effect of subcooling. Therefore, this work elucidates the combined effects of heater orientation and liquid subcooling on the relative stability of boiling.

\section{Experimental}

The experimental setup is the same as that employed in Ref. [31] except that the surface orientation can be adjusted freely. Fig. 1a schematically depicts the setup. The working liquid is methanol with a purity exceeding $99 \%$, which was not degassed prior to use. The constant head maintained in the storage tank (1) and globe valve (7) forced methanol to flow through the heat exchanger (3) and the flow meter (4) to the testing section (5). The receiving tank (8) was open to atmos- phere through a condenser (10). The used methanol in the receiving tank was pumped back to the storage tank by a gear pump (9). The flow path through storage tank, testing section and the receiving tank formed the boiling loop. Liquid subcooling was adjusted and maintained by the heat exchanger (3).

Fig. $1 \mathrm{~b}$ presents the orientation angle, $\theta$, which
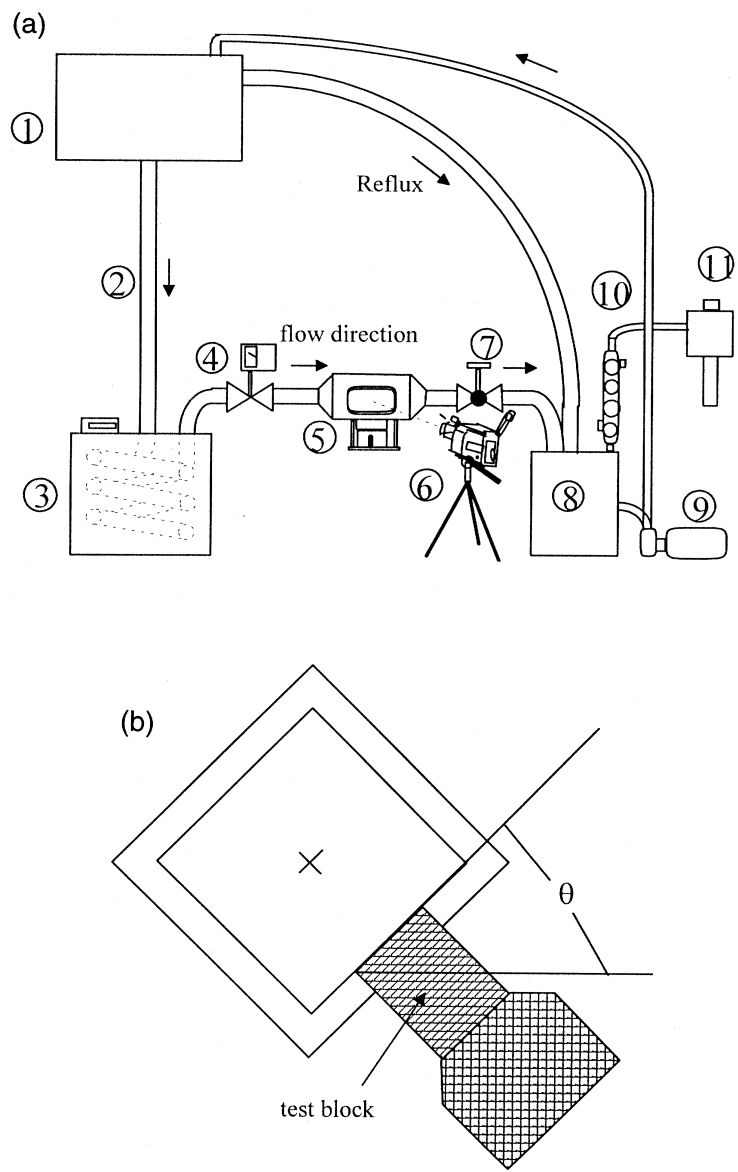

Fig. 1. (a) Schematics of boiling apparatus: (1) storage tank, (2) pipe, (3) heat exchanger, (4) flow meter, (5) testing section, (6) camera, (7) globe valve, (8) receiving tank, (9) gear pump, (10) condenser, (11) aspirator; (b) orientation of the heater surface. 
measures the rotation around the horizontal axis that is perpendicular to the flow direction. The fluid always flows parallel with the heater surface. Herein, all tests were conducted under atmospheric pressure, with methanol flowing at a rate of $20 \mathrm{~kg} / \mathrm{m}^{2} \mathrm{~s}$, producing a flow velocity of $0.025 \mathrm{~cm} / \mathrm{s}$. Such a low velocity is less than the critical value $(0.08 \mathrm{~m} / \mathrm{s})$ proposed by Brusttar et al. [24]. Therefore, the present boiling system resembles a pool boiling system. The cross flow simply sweeps away the generated vapor bubbles from the testing section.

Lin et al. [31] provided details of the testing section and those of the heating assembly. The testing block was made of pure copper, a majority of which $(93 \%$ from the bottom) was divided into two separated parts with a gap of $5 \mathrm{~mm}$ in between. Only the top $7 \%$ of the testing block was connected (of thickness $2 \mathrm{~mm}$ ). Insulation was employed in the gap to prevent heat conduction among the bottom portions of the testing block. Axial heat conduction was therefore permitted only in the top (or 'bridge') connection section. The two heating blocks under the testing block were equipped with cartridge heaters that can provide joule heat separately. The joule heat would thereby dissipate partially by surface boiling, and exchange the rest of heat with the other block if a temperature gradient existed between them. Temperatures at 24 positions in the testing block were measured by thermocouples, whose readings were sent at a rate of $1 \mathrm{~Hz}$ to a data acquisition system connected to a personal computer.

The experimental procedures were as follows. First, all bottom cartridge heaters were set at a voltage of $V_{1}$ to let the entire heating surface enter the nucleate boiling mode. Next, the voltage of the cartridge heaters in one of the bottom heating blocks was set at a high voltage of $V_{2}$, forcing the corresponding top surface to enter film boiling. Once a visible film boiling was established on the boiling surface, the voltage of the bottom cartridge heaters was decreased from $V_{2}$ to $V_{3}$ to prevent a burnout of the sealing silicon rubber. Notably, the voltage for the other heating block was always maintained at $V_{1}$. The high temperature under film boiling mode caused a large axial heat conduction across the near-surface bridge connection to the other block.

Co-existing heat fluxes ( $q_{\mathrm{N}}$ and $q_{\mathrm{F}}$ ), and the equilibrium heat flux $\left(q_{\mathrm{c}}\right)$ were determined according to procedure described elsewhere [31,32]. For clarity, the procedure is briefly described as follows. The portion of heating surface at which the film boiling mode was initially imposed is referred to as section F. The other section on which nucleate boiling mode was imposed, referred to as section $\mathrm{N}$. The film boiling mode set up at section $\mathrm{F}$ would compete with the nucleate boiling mode at section $\mathrm{N}$ via the axial heat conduction through the bridge section. The film boiling at section
$\mathrm{F}$ which wins is more stable than the nucleate boiling at section N. Otherwise, film boiling mode at section $\mathrm{F}$ becomes less stable than the nucleate boiling at section $\mathrm{N}$. The bottom heat fluxes at section $\mathrm{N}$ and section $\mathrm{F}$ can be adjusted by setting different $V_{1}$ and $V_{3}$ values. The corresponding bottom heat fluxes in which nucleate boiling and film boiling are equally stable are referred to as $q_{\mathrm{N}}$ and $q_{\mathrm{F}}$, respectively. Rather than independent of each other, $q_{\mathrm{N}}$ and $q_{\mathrm{F}}$ correlate with each other (as discussed later). The condition where $q_{\mathrm{N}}=q_{\mathrm{F}}$ is used to determine the so-called 'equilibrium heat flux', $q_{\mathrm{c}}$.

The method of Kline and McClintock [33] was adopted to estimate the uncertainties of heat flux and surface temperature measurements. The uncertainties in the heater surface temperature and the associated heat flux when constructing boiling curves were estimated as $\pm 7 \%$ and $\pm 11 \%$, respectively. The mass flow rates exhibited an uncertainty of approximately $\pm 5 \%$, while for fluid temperature measurement, $\pm 1 \mathrm{~K}$. The error in orientation angle was less than $2^{\circ}$.

\section{Results and discussion}

\subsection{Time evolutions}

Surface heat fluxes and wall superheat were estimated by solving the transient heat conduction equation with the thermocouple readings as boundary conditions. Fig. 2 depicts the time evolutions of surface superheat at $\theta=90^{\circ}$ under saturated condition or $\Delta T_{\text {sub }}=10 \mathrm{~K}$. While $V_{1}=160 \mathrm{~V}$, the $V_{3}$ values are

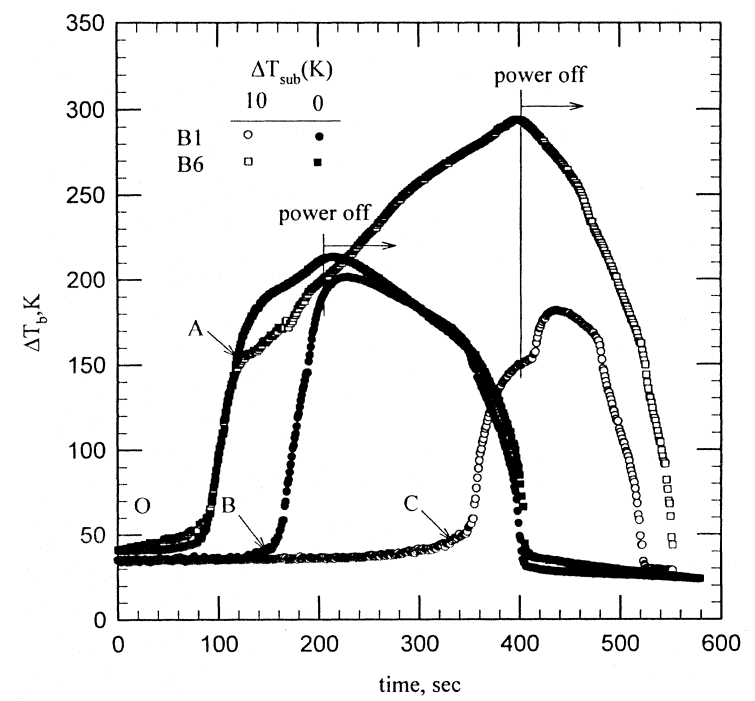

Fig. 2. Time evolution of extrapolated surface temperature data at section $\mathrm{F}$ and section $\mathrm{N}$. 
$120 \mathrm{~V}$ for the saturated, and $180 \mathrm{~V}$ for the subcooled case, both slightly exceeding their corresponding CHF conditions. The surface heat fluxes under nucleate boiling mode are $0.93 \mathrm{MW} / \mathrm{m}^{2}$ for saturated boiling and $1.12 \mathrm{MW} / \mathrm{m}^{2}$ for subcooled boiling; while those under film boiling mode are 0.24 and $0.55 \mathrm{MW} / \mathrm{m}^{2}$, respectively. Restated, the corresponding heat fluxes are all less for the saturated than for the subcooled case.

According to Fig. 2, the temperature-rising phase (OA, during which film boiling appears) initially evolves closely regardless of liquid subcooling. After passing point $\mathrm{A}$, an apparent deviation occurs. At $\Delta T_{\text {sub }}=10 \mathrm{~K}$, the surface temperature increases at a lower rate than with the saturated case. For example, the time required to induce burnout of section $\mathrm{N}$ is approximately $75 \mathrm{~s}$ for the saturated case (point B), and becomes $315 \mathrm{~s}$ when $\Delta T_{\text {sub }}=10 \mathrm{~K}$ (point $\mathrm{C}$ ). Such a difference is attributed to the more efficient film boiling mode at section $\mathrm{F}$ and transition boiling mode close to the bridge regime for a subcooled liquid, which reduces the axial heat conduction into a low-temperature regime (section $\mathrm{N}$ ).

The wall superheat of section $\mathrm{N}$ was still rising for both saturated boiling and subcooling boiling after the heaters were turned off. This observation is attributed to the conduction of residual heat from section $\mathrm{F}$ that is still sufficient to bring the section $\mathrm{N}$ into a higher temperature regime.

Tests with other heater orientations reveal a similar trend in temperature evolution except for the case of $\theta=180^{\circ}$, where the heater is facing downwards. A large vapor film that appears on the boiling surface is driven downstream by the forced flow. A relatively greater uncertainty exists in terms of determining the critical conditions of co-existence of different boiling modes.

\subsection{Co-existing heat fluxes and equilibrium heat flux}

Fig. 3 presents the $\left(q_{\mathrm{N}}, q_{\mathrm{F}}\right)$ sets for $\theta=0-180^{\circ}$ and $\Delta T_{\text {sub }}=0-20 \mathrm{~K}$. Three points are worth mentioning. First, decreasing $q_{\mathrm{N}}$ increases $q_{\mathrm{F}}$, which is expected since the nucleate boiling at a higher surface heat flux is less stable in nature. Second, at a fixed $q_{\mathrm{N}}, q_{\mathrm{F}}$ initially increases with orientation angle $\theta$, after passing a maximum at $\theta=90^{\circ}$ and, then, decreases as $\theta$ exceeds $90^{\circ}$. Notably, $q_{\mathrm{F}}$ markedly drops between $\theta=$ $135^{\circ}$ and $180^{\circ}$. Third, at fixed $q_{\mathrm{N}}$ and $\theta$, increasing $\Delta T_{\text {sub }}$ yields a lower $q_{\mathrm{F}}$. According to Lin et al. [31], a larger $q_{\mathrm{N}}$ denotes a (relatively) more stable nucleate boiling mode than with the corresponding film boiling mode, and vice versa.

Lin and Lee [29] demonstrated the feasibility of applying the equal-area criterion to interpret the multimode boiling data (the Maddock's criterion). With each $q_{\mathrm{N}}$ and $q_{\mathrm{F}}$ set in Fig. 3 nucleate boiling can stea-

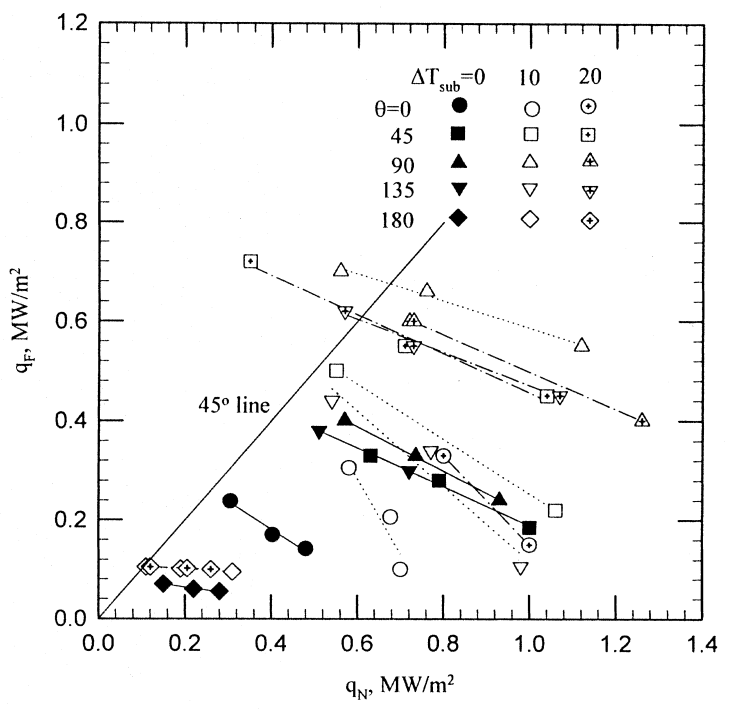

Fig. 3. Co-existing heat fluxes at various liquid subcooling and orientation.

dily coexist with the film boiling on the heating surface, Lin et al. [31] proposed that the intersection between the $\left(q_{\mathrm{N}}, q_{\mathrm{F}}\right)$ data set in Fig. 3 and the $45^{\circ}$-line estimates the equilibrium heat flux, $q_{\mathrm{c}}$, where $q_{\mathrm{N}}=$ $q_{\mathrm{F}}=q_{\mathrm{c}} . q_{\mathrm{c}}$ is unique for a given heater/fluid combination (at fixed fluid velocity). This can be employed as an index to the relative stability between nucleate and film boiling modes. A higher $q_{\mathrm{c}}$ implies a lesser likelihood of burnout, and vice versa.

Fig. 4 displays the $q_{\mathrm{c}}$ versus $\theta$ plot with $\Delta T_{\text {sub }}$ as a parameter. Notably, a local maximum occurs at $\theta=$ $90^{\circ}$. Restated, the nucleate boiling mode exhibits the highest stability relative to the corresponding film boiling mode when the heater is turned vertically on its side. The effect pre-dominates at $\Delta T_{\text {sub }}=20 \mathrm{~K}$. The corresponding $q_{\mathrm{c}}$ at $\theta=90^{\circ}$ and $\Delta T_{\text {sub }}=20 \mathrm{~K}$ is nearly 2.5 times that at $\theta=0^{\circ}$ and $\Delta T_{\text {sub }}=0 \mathrm{~K}$. Therefore, a surface turned on its side up with the coolest liquid would exhibit the highest relative stability of nucleate boiling mode, thereby ensuring the safety of the boiling process. At $\Delta T_{\text {sub }}=20 \mathrm{~K}, q_{\mathrm{c}}$ varies sightly with orientation as $\theta<90^{\circ}$. Such an occurrence suggests a further advantage for employing subcooled boiling.

The $q_{\mathrm{c}}$ at $\theta=180^{\circ}$, i.e., a facing-downward heater, is rather low. Therefore, the heater could easily burnout. Liquid subcooling has only a secondary effect. Notably, using a subcooled liquid only slightly enhances the relative stability of nucleate boiling mode for $180^{\circ}$.

\subsection{Discussions}

Lin et al. [31] discussed the effects of heater orien- 


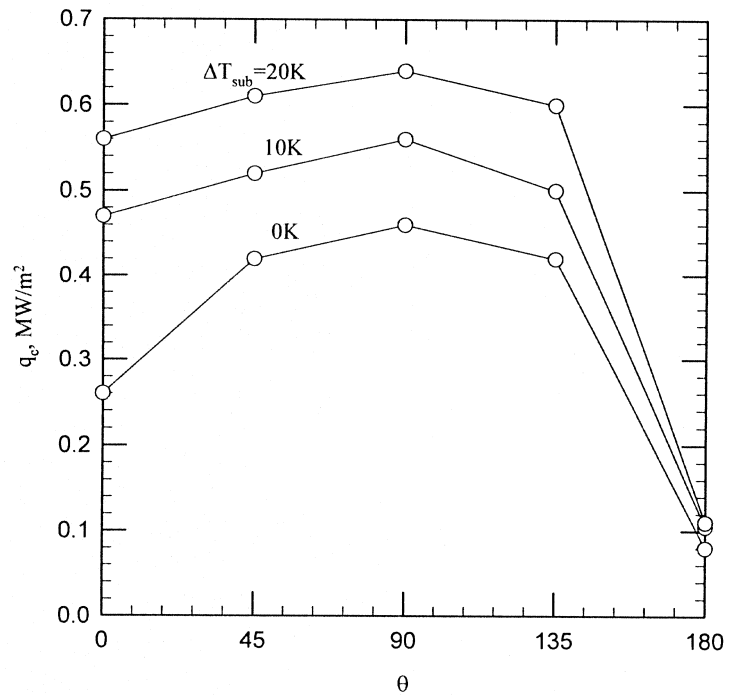

Fig. 4. Equilibrium heat flux versus $\theta$ plot.

tation at a saturated condition on the basis of the equal-area criterion. Based on the heat conduction equation and the no-flux boundary conditions, the equal-area criterion can be stated as follows [29]:

$I=\int_{T_{\mathrm{N}}}^{T_{\mathrm{F}}}\left(q_{\mathrm{b}}-q_{\mathrm{c}}\right) \mathrm{d} T=0$

where $T_{\mathrm{F}}$ and $T_{\mathrm{N}}$ are the temperature under film and nucleate boiling, and $q_{\mathrm{b}}$, the boiling heat flux, respectively. According to Nishio and Chandratilleke [11], $q_{\mathrm{c}}$ is determined by the whole boiling curve $\left(q_{\mathrm{b}}\right)$ : the nucleate boiling curve, transition boiling curve, and film boiling curve as well as the CHF and MHF. The effects of liquid subcooling and/or orientation on $q_{\mathrm{c}}$ are discussed on the basis of the shift in the whole boiling curves as follows.

Fig. 5 depicts the boiling curves at $\theta=0-180^{\circ}$ and $\Delta T_{\text {sub }}=0$ and $20 \mathrm{~K}$, respectively. For each test, there are two average transition boiling curves: one from $\mathrm{CHF}$ to film boiling curve, and the other from MHF back to nucleate boiling curves. A detailed discussion of the average and true transition boiling curve can be found in [26]. These transition boiling curves are not included in Fig. 5 for clarity sake. Liquid subcooling only slightly affects the nucleate boiling and film boiling curves. However, both $\mathrm{CHF}$ and $\mathrm{MHF}$, particularly for the former, markedly increase with subcooling. These experimental findings closely correspond to previous literature [34]. Effects of heater's orientation are generally in line with those reported in [31]. For example, CHF has the following sequence: $\theta=90^{\circ}>45^{\circ}>0^{\circ}>135^{\circ} \gg 180^{\circ}$. However, under a subcooled condition, the enhancement of CHF owing

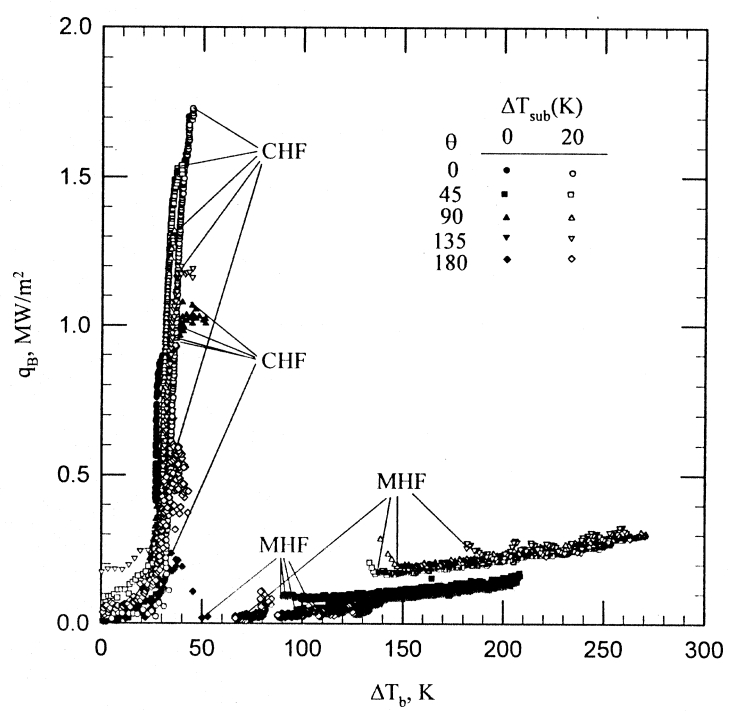

Fig. 5. Nucleate and film boiling curves. The arrows denote the measured CHF and MHF points.

to liquid subcooling compensates for the effects of heater orientation. Correspondingly, $\mathrm{CHF}$ has the following sequence: $\theta=0^{\circ}>45^{\circ}>90^{\circ}>135^{\circ} \gg 180^{\circ}$. These results correlate with previous investigations $[3,11,16]$. Table 1 lists the $\mathrm{CHF}$ and $\mathrm{MHF}$ data. Haddad and Cheung [18] observed that CHF increases as $\theta$ decreases from 180 to $90^{\circ}$. Although Brusstar et al. [24] observed a similar trend, their definition of orientation differs from that defined in this work.

The transition boiling curve discussed herein denotes the true, but the average transition boiling curve. Meanwhile, the former cannot be directly obtained from the heat conduction-controlled apparatus [35]. Although unavailable, the true transition boiling curves should connect the $\mathrm{CHF}$ and $\mathrm{MHF}$ points in Fig. 5 and should shift together with these two critical points. Restated, for saturated methanol, the true transition boiling curves would move upward and rightward with orientation until the surface is turned vertically on its side $\left(\theta=90^{\circ}\right)$, then moves back with

Table 1

The CHF and MHF data at various heater orientations and liquid subcooling ${ }^{\mathrm{a}}$

\begin{tabular}{lllll}
\hline & CHF (0 K) & CHF (20 K) & MHF (0 K) & MHF (20 K) \\
\hline $0^{\circ}$ & 0.96 & 1.73 & 0.04 & NA \\
$45^{\circ}$ & 1.01 & 1.54 & 0.10 & 0.27 \\
$90^{\circ}$ & 1.08 & 1.31 & 0.11 & 0.22 \\
$135^{\circ}$ & 0.95 & 1.20 & 0.04 & 0.19 \\
$180^{\circ}$ & 0.24 & 0.59 & 0.02 & 0.03 \\
\hline
\end{tabular}

${ }^{\text {a }}$ All heat fluxes are reported in $\mathrm{MW} / \mathrm{m}^{2}$. 
an increasing $\theta$. Under a subcooled condition, the transition boiling curve shifts downward with an increasing orientation angle.

In sum, above results suggests that (1) neither the orientation nor the liquid subcooling markedly affects the nucleate boiling and film boiling curves; and (2) both the orientation and liquid subcooling significantly influence the transition boiling curves that connect the $\mathrm{CHF}$ and MHF points. According to the equal-area criterion, the change in $q_{\mathrm{c}}$ observed in Fig. 4 is thereby attributed to the shift of the transition boiling curve. Restated, a more efficient transition mode with subcooled liquid favors a higher $q_{\mathrm{c}}$, yielding a safer nucleate boiling mode.

\section{Conclusions}

This work investigates the relative stability between nucleate boiling and film boiling modes on an inclined surface under a forced flow, with particular emphasis on the effects of liquid subcooling. At different heater configurations, the co-existing heat fluxes are found at various liquid subcooling temperatures, from which, the equilibrium heat flux is identified. Nucleate boiling mode exhibits the highest stability in relation to the corresponding film boiling mode when the liquid is at the highest subcooling and the heater is turned vertically on its side. The subcooled methanol subject to nucleate boiling on a vertically oriented heater is thereby much more stable than the saturated methanol boiled on a horizontal heater. In contrast to the other orientations, the face-downward surface is easy to burnout. In addition, applying a subcooled liquid barely enhances the relative stability of nucleate boiling mode for $180^{\circ}$. Shifts in CHF and MHF, together with the transition boiling curve, interpret the change in relative stability at varying heater orientations and liquid subcooling.

\section{References}

[1] P.M. Githinji, R.H. Sabersky, Some effects on the orientation of the heating surface in nucleate boiling, ASME J. Heat Transfer 85 (1963) 379.

[2] B.D. Marcus, D. Dropkin, The effects of surface configuration on nucleate boiling heat transfer, Int. J. Heat Mass Transfer 6 (1963) 863-867.

[3] D.N. Lyon, Boiling heat transfer and peak heat nucleate boiling fluxes in saturated liquid helium between the $\lambda$ and critical temperatures, Adv. Cryogenic Engng 19 (1965) 371.

[4] R.P. Anderson, L. Bova, The role of down facing burnout in post-accident heat removal, Trans. Am. Nucl. Soc 14 (1971) 294-304.
[5] I.P. Vishnev, I.A. Filatov, Ya.G. Vinokur, V.V. Gorokhov, G.C. Svalov, Study of heat transfer in boiling of helium on surfaces with various orientations, Heat Transfer-Sov. Res 8 (1976) 104-108.

[6] L.T. Chen, Heat transfer to pool boiling feron from inclined heating plate, Lett. Heat Mass Transfer 5 (1978) 111-120.

[7] D.S. Jung, J.E.S. Venart, A.C.M. Sousa, Effects of enhanced surfaces and surface orientation on nucleate and film boiling heat transfer in R-11, Int. Heat Mass Transfer 30 (1987) 2627-2639.

[8] N. Seki, S. Fukushako, K. Torikoshi, Experimental study on the surface orientation of heating circular plate on film boiling heat transfer for fluorocarbon refrigerant R-11, ASME J. Heat Transfer 100 (1978) 624-628.

[9] K. Nishikawa, Y. Fujita, S. Uchida, H. Ohta, Effects of surface orientation on nucleate boiling heat transfer, Int. J. Heat Mass Transfer 27 (1984) 1559-1571.

[10] C. Beduz, R.G. Scurlock, A.J. Sousa, Angular dependence of boiling heat transfer mechanisms in liquid nitrogen, Adv. Cryogenic Engng 33 (1988) 363-370.

[11] S. Nisho, D. Chandratilleke, Steady-state pool boiling heat transfer to saturated liquid helium at atmospheric pressure, JSME Int. J. Ser. B 32 (1989) 639-645.

[12] Z. Guo, M.S. El-Genk, An experimental study of saturated pool boiling from downward facing and inclined surfaces, Int. J. Heat Mass Transfer 35 (1992) 2109 2117.

[13] M.S. El-Genk, Z. Guo, Effects of liquid subcooling on the quenching of inclined and downward facing flat surfaces in water, AIChE Symp. Ser. No 288 (88) (1992) 241-248.

[14] M.S. El-Genk, Z. Guo, Transient boiling from inclined and downward facing surfaces in a saturated pool, Int. J. Refrig 16 (1993) 414-422.

[15] M.S. El-Genk, A.G. Glebov, Transient boiling from downward facing curved surfaces, Int. J. Heat Mass Transfer 38 (1995) 2209-2224.

[16] J.Y. Chang, S.M. You, Heater orientation effects on pool boiling of micro- porous-enhanced surfaces in saturated FC-72, ASME J. Heat Transfer 118 (1996) 937943.

[17] F.B. Cheung, K.H. Haddad, A hydrodynamic critical heat flux model for saturated pool boiling on a downward facing curved heating surface, Int. J. Heat Mass Transfer 40 (1997) 1291-1302.

[18] K.H. Haddad, F.B. Cheung, Steady-state subcooled nucleate boiling on a downward-facing hemispherical surface, ASME J. Heat Transfer 120 (1998) 365-370.

[19] S.H. Yang, W.P. Baek, S.H. Chang, Pool-boiling critical heat flux of water on small plates: effects of surface orientation and size, Int. Comm. Heat Mass Transfer 24 (1997) 1093-1102.

[20] J.H. Lienhard, On the two regimes of nucleate boiling, ASME J. Heat Transfer 107 (1985) 262-264.

[21] J.H. Lienhard, A Heat Transfer Textbook, PrenticeHall, New York, 1987.

[22] C.O. Gersey, I. Mudawar, Orientation effects on critical heat flux from discrete, in-line heat sources in a flow channel, ASME J. Heat Transfer 115 (1993) 973-985.

[23] M.J. Brusstar, H. Merte, Effect of buoyancy on the 
critical heat flix in forced convection, AIAA J. Thermophys. Heat Transfer 8 (1994) 322-328.

[24] M.J. Brusstar, H. Merte, R.B. Keller, B.J. Kirby, Effect of heater surface orientation on the critical heat flux-I. An experimental evaluation of models for subcooled pool boiling, Int. J. Heat Mass Transfer 40 (1997) 40074019.

[25] M.J. Brusstar, H. Merte, Effect of heater surface orientation on the critical heat flux-II. A model for pool and forced convection subcooled boiling, Int. J. Heat Mass Transfer 40 (1997) 4021-4030.

[26] S.M. Lu, D.J. Lee, The effects of heating methods on pool boiling, Int. J. Heat Mass Transfer 34 (1991) 127134.

[27] D.J. Lee, S.M. Lu, Two-mode boiling on a horizontal heating wire, AIChE J. 38 (1992) 1115-1128.

[28] D.J. Lee, Two-mode boiling on a horizontal heating wire: effects of liquid subcoolings, Int. J. Heat Mass Transfer 41 (1998) 2925-2928.

[29] W.W. Lin, D.J. Lee, Relative stability between nucleate and film boiling on a non-uniformly heated flat surface, ASME J. Heat Transfer 119 (1997) 326-331.

[30] W.W. Lin, D.J. Lee, Methanol flow boiling over a nonuniformly heated flat plate, J. Ch. I. Ch. E 29 (1998) 27-32.

[31] W.W. Lin, J.C. Yang, D.J. Lee, Stability characteristics of methanol flowing over a non-uniformly heated surface, Int. J. Heat Mass Transfer 41 (1998) 40094023.

[32] W.W. Lin, J.C. Yang, D.J. Lee, Relative stability of boiling on a flat plate: effects of heater orientation, ASME J. Heat Transfer 121 (1999) 484-486.

[33] S.J. Kline, F.A. McClintock, Description of uncertainties in single sample experiments, Mech. Engng 75 (1) (1953) 3-8.

[34] D.J. Lee, Effects of heater properties, heating methods, and subcooling on pool boiling of liquids. Ph.D. thesis, National Taiwan University, Taipei, Taiwan, 1989.

[35] J. Blum, W. Marquardt, Stability of boiling systems, Int. J. Heat Mass Transfer 39 (1996) 3021-3033. 